\title{
Plasma levels of YKL-40 as a prognostic factor in childhood acute lymphoblastic leukemia
}

\author{
ALINNE AYULIETH RIVAS-ALARCÓN ${ }^{1}$, YAZMIN GÓMEZ-GÓMEZ ${ }^{1}$, JORGE ORGANISTA-NAVA ${ }^{1}$, \\ MARCO ANTONIO JIMÉNEZ-LÓPEZ ${ }^{2}$, ANA BERTA RIVERA-RAMÍREZ ${ }^{2}$, \\ ELOISA IBARRA-SIERRA ${ }^{2}$, MÓNICA VIRGINIA SAAVEDRA-HERRERA ${ }^{2}$, \\ BERENICE ILLADES-AGUIAR ${ }^{1}$ and MARCO ANTONIO LEYVA-VÁZQUEZ ${ }^{1}$ \\ ${ }^{1}$ Laboratorio de Biomedicina Molecular, Facultad de Ciencias Químico Biológicas, \\ Universidad Autónoma de Guerrero, Chilpancingo, Guerrero 39070; ${ }^{2}$ Departamento de Investigación, \\ Instituto Estatal de Cancerología ‘Arturo Beltrán Ortega’, Acapulco, Guerrero 39570, México
}

Received August 14, 2020; Accepted January 27, 2021

DOI: $10.3892 / \mathrm{mco} .2021 .2330$

\begin{abstract}
YKL-40, also known as chitinase-3-like protein 1 (CHI3L1), is an inflammatory glycoprotein secreted by different types of cells, such as inflammatory cells. The levels of this protein are elevated in the serum or plasma of patients with different types of cancer, and high concentrations are associated with poor prognosis and short survival in patients with liver, breast, lung, bladder and endometrial cancers. In Mexico, acute lymphoblastic leukemia (ALL) is the most common type of cancer affecting the pediatric population. The prognosis of patients with ALL is difficult to establish. Hence, the objective of the present study was to analyze the plasma levels of YKL-40 in Mexican children with ALL and investigate its role as a prognostic factor. A case-control study was performed in a population of 90 children aged 1-18 years, among whom 45 had ALL and 45 were hematologically healthy. The levels of YKL-40 in plasma samples were measured using ELISA and were found to be significantly higher in children with ALL compared with those in controls $(\mathrm{P}<0.0001)$. Children with ALL who had high plasma levels of YKL-40 ( $\geq 36.34 \mathrm{ng} / \mathrm{ml})$ had shorter survival compared with those with low levels $(<36.34 \mathrm{ng} / \mathrm{ml} ; \mathrm{P}<0.05)$. The findings of the present study revealed that the YKL-40 plasma level, age/initial leukocyte count and central nervous system invasion were associated with the prognosis of children with ALL [odds ratio $(\mathrm{OR})=6.06$, 95\% confidence interval $(\mathrm{CI}): 1.1-31.6, \mathrm{P}=0.03$; $\mathrm{OR}=8.53,95 \%$ CI: $1.2-58.2, \mathrm{P}=0.03$; and $\mathrm{OR}=6.45,95 \% \mathrm{CI}: 1.01-41.2, \mathrm{P}=0.04$,
\end{abstract}

Correspondence to: Professor Marco Antonio Leyva-Vázquez, Laboratorio de Biomedicina Molecular, Facultad de Ciencias Químico Biológicas, Universidad Autónoma de Guerrero, Av. Lázaro Cárdenas S/N Ciudad Universitaria, Chilpancingo, Guerrero 39070, México

E-mail: leyvamarco13@gmail.com

Key words: acute lymphoblastic leukemia, childhood, YKL-40, prognosis, survival respectively]. Therefore, YKL-40 plasma levels may serve as a prognostic biomarker in pediatric patients with ALL.

\section{Introduction}

Childhood cancer is a major public health challenge in Mexico, with $>5,000$ new cases diagnosed annually, and is the second leading cause of mortality among children aged 5-14 years $(1,2)$. In the Mexican state of Guerrero, acute lymphoblastic leukemia (ALL) is the most common malignancy in children $(1,3)$. The prognosis of patients with ALL may be partially predicted based on certain clinical characteristics, such as age, karyotype, cytogenetic alterations, immunophenotype, sex and initial leukocyte count $(4,5)$. Hence, it is important to identify novel and more reliable prognostic biomarkers for leukemia. YKL-40, also known as chitinase-3-like protein 1 (CHI3L1), is a secreted inflammatory glycoprotein produced by different types of cells, such as inflammatory cells (neutrophils and macrophages), stem cells, vascular smooth muscle cells and chondrocytes (6). YKL-40 is involved in different cellular processes, such as cancer cell proliferation, survival and invasiveness, peritumoral inflammation, angiogenesis and remodeling of the extracellular matrix (7). High serum or plasma levels of YKL-40 have been detected in patients with various types of cancer. This upregulation has been linked to shorter progression-free and overall survival times in patients with glioma, melanoma, pancreatic, lung and breast cancer (8-12).

YKL-40 has also been found to be elevated in the serum or plasma of patients with non-cancerous diseases that are characterized by inflammation, tissue remodeling and fibrosis (13), including rheumatic diseases (14) and lung diseases, such as asthma (15) and chronic obstructive pulmonary disease (16). In cardiovascular diseases, YKL-40 has been shown to be expressed by macrophages in atherosclerotic plaques (17). In patients with diabetes, elevated levels of YKL-40 have been associated with insulin resistance (18).

A previous study revealed that high serum levels of YKL-40 in adult patients with acute myeloblastic leukemia (AML) led to 
shorter survival times, and that the serum level of this protein was an independent predictor of survival in patients with AML (19). In another study in adult patients with leukemia, the YKL-40 plasma levels were found to differ significantly between leukemia patients and healthy individuals (20).

Therefore, YKL-40 protein has been attracting a notable amount of attention as a biomarker of poor prognosis in patients with cancer $(7,13)$. However, the role of YKL-40 as prognostic biomarker in childhood ALL has not been explored to date. Therefore, the present study was undertaken to analyze the plasma levels of YKL-40 in Mexican children with ALL and investigate its role as a prognostic factor.

\section{Materials and methods}

Study population. A case-control study in a population of children aged 1-18 years was performed. The patients were treated at the Pediatric Oncology Clinic of the State Cancer Institute 'Dr. Arturo Beltran Ortega' in Acapulco, México, between July 2016 and September 2018. The study involved 45 children who had not received treatment and who were recently diagnosed with ALL according to the morphological findings of bone marrow aspirate and the criteria reported by Organista et al in 2015 (21).

At the time of admission of each patient, a physical examination was performed to determine their general health status. In addition, genetic and biochemical tests were performed, as well as imaging tests, such as ultrasound, nuclear magnetic resonance or computed axial tomography, in order to assess the involvement of other organs. Furthermore, all patients included in the study underwent a procalcitonin test, as well as blood and urine cultures to rule out secondary infections. This was taken into account, in order to rule out the possible effects of inflammation on YKL-40 levels.

Overall survival was determined as the time between the date of study registration and the date of death from any cause or the date of the last contact $(21,22)$. Survival data were obtained by reviewing the clinical records. Risk classification in children with ALL was as follows: i) Low-risk, children aged 1-10 years with a leukocyte count $<50,000 / \mathrm{mm}^{3}$; and ii) high-risk, children aged $<1$ and $>10$ years with a leukocyte count $>50,000 / \mathrm{mm}^{3}$.

Patients with ALL were divided into groups with low and high expression of YKL-40. The median expression of YKL-40 (36.34 ng/ml) was used as the cut-off point to divide the 45 patients with ALL into these two groups. Those who expressed YKL-40 at levels $<36.34 \mathrm{ng} / \mathrm{ml}$ were assigned to the downregulation group $(\mathrm{n}=20)$, and those with expression levels $>36.34 \mathrm{ng} / \mathrm{ml}$ were assigned to the upregulation group $(n=25)$.

Patients were treated with VDCPM (vincristine, daunorubicin, cyclophosphamide, prednisone and intrathecal methotrexate) or VDLPM (vincristine, daunorubicin, asparaginase, prednisone and intrathecal methotrexate) regimens according to the protocol reported by Organista et al (21). Following the aforementioned treatment schemes and a follow-up of $\sim 36$ months, $64.5 \%$ of children with ALL survived and $35.5 \%$ succumbed to the disease.

The control group comprised 45 hematologically healthy children aged 1-18 years, who visited the Health Center 'Dr. Ramón Carreto Leyva' in Chilpancingo, México, for reasons such as vaccination, weight and height monitoring, and medical consultation. Blood count measurements confirmed normal leukocyte count $\left(4.5-11.0 \times 10^{3} / \mathrm{mm}^{3}\right)$.

Peripheral blood samples $(5 \mathrm{ml})$ were collected from both study groups. The parents or guardians of all the subjects signed informed consent forms; the original study protocol was approved by the Ethics Committee of the State Cancer Institute of the State of Guerrero. All procedures followed were in accordance with the ethical standards of the responsible committees on human experimentation (institutional and national) and with the principles outlined in the Helsinki Declaration.

The blood samples used in both study groups were obtained through venous puncture and were collected in tubes with EDTA as the anticoagulant (BD Vacutainer ${ }^{\mathrm{TM}}$; Becton-Dickinson and Company). Plasma was separated from each sample by centrifugation at $1,200 \mathrm{x}$ g for $10 \mathrm{~min}$ at $4^{\circ} \mathrm{C}$ and stored at $-70^{\circ} \mathrm{C}$ until use.

Determination of YKL-40 plasma levels by ELISA. YKL-40 plasma levels were measured using ELISA (Human CHI3L1 ELISA Kit, cat. no. DC3L10; R\&D Systems, Inc.), according to the manufacturer's instructions. Plasma samples were diluted 1:10 [90 $\mu \mathrm{l}$ assay diluent $\operatorname{RD} 5 \mathrm{P}(1: 5)+10 \mu \mathrm{l}$ of plasma]. The optical density of each well was determined using a microplate reader (MultiSkan Go; Thermo Fisher Scientific, Inc.) at a wavelength of $450 \mathrm{~nm}$. The sensitivity of the ELISA technique was $3.55 \mathrm{pg} / \mathrm{ml}$. All samples were measured in duplicate.

Statistical analysis. Statistical analysis was performed using SPSS version 25.0 (IBM Corp.) and GraphPad Prism version 5.0 (GraphPad Software, Inc.). The Mann-Whitney U-test was used to identify significant differences between study populations. Kaplan-Meier curves were constructed to analyze the effect of YKL-40 plasma levels on the survival of patients with ALL, and the differences were compared using log-rank tests. A univariate logistic regression model was also used to identify factors associated with survival in children with ALL, adjusted for sex, presence of cytogenetic alterations such as translocations, risk by age and initial leukocyte count, invasion of the central nervous system (CNS) and YKL-40 plasma levels. Those associated factors were included in a second multivariate logistic regression model. $\mathrm{P}<0.05$ was considered to indicate statistically significant differences.

\section{Results}

General characteristics of the study population. Overall, 45 plasma samples from children with ALL as well as 45 control samples from healthy children were collected. The characteristics of the included subjects are summarized in Table I.

YKL-40 plasma levels in children with ALL. The median YKL-40 plasma level in children with ALL was $59.7 \mathrm{ng} / \mathrm{ml}$, which was significantly higher compared with that in children without ALL (22.5 ng/ml; P<0.0001; Fig. 1A).

Clinical characteristics of children with ALL and identification of prognostic factors. The pathological parameters associated with survival in children with ALL in the present study were as follows: Age, sex, initial leukocyte count, 
Table I. General characteristics and clinical data of children with and without ALL.

\begin{tabular}{|c|c|c|}
\hline Variables & Children with ALL $(n=45)$ & Children without ALL $(n=45)$ \\
\hline Age, years $($ mean $\pm S D)$ & $8.7 \pm 4.9$ & $9.5 \pm 4.0$ \\
\hline Leukocyte count, $/ \mathrm{mm}^{3}$ & $24,400(11,950-63,925)^{\mathrm{a}}$ & $6,650(5,700-8,325)^{\mathrm{a}}$ \\
\hline \multicolumn{3}{|l|}{ Sex, n $(\%)$} \\
\hline Male & $24(53.3)$ & $21(46.7)$ \\
\hline Female & $21(46.7)$ & $24(53.3)$ \\
\hline \multicolumn{3}{|l|}{ Patient status, n (\%) } \\
\hline Alive & $29(64.4)$ & $45(100.0)$ \\
\hline Deceased & $16(35.6)$ & - \\
\hline \multicolumn{3}{|l|}{ ALL type, n (\%) } \\
\hline Type B & $42(93.0)$ & - \\
\hline Type T & $3(7.0)$ & - \\
\hline Translocation, n (\%) & $10(24.0)$ & \\
\hline $\mathrm{t}(1 ; 19)$ & $2(4.0)$ & - \\
\hline $\mathrm{t}(9 ; 22)$ & $5(11.0)$ & - \\
\hline TAL1 & $1(3.0)$. & - \\
\hline $\mathrm{t}(10 ; 11)$ & $1(3.0)$ & - \\
\hline $\mathrm{t}(12 ; 21)$ & $1(3.0)$ & \\
\hline None & $35(76.0)$ & \\
\hline \multicolumn{3}{|l|}{ Risk according to age, $\mathrm{n}(\%)$} \\
\hline Low (1-10 years) & $24(53.3)$ & - \\
\hline High $(<1$ and $>10$ years $)$ & $21(46.7)$ & - \\
\hline \multicolumn{3}{|c|}{ Risk according to leukocyte count at diagnosis, $\mathrm{n}(\%)$} \\
\hline Low $\left(<50,000 / \mathrm{mm}^{3}\right)$ & $30(66.7)$ & - \\
\hline High $\left(\geq 50,000 / \mathrm{mm}^{3}\right)$ & $15(33.3)$ & - \\
\hline \multicolumn{3}{|l|}{ CNS invasion, $\mathrm{n}(\%)$} \\
\hline Yes & $14(31.1)$ & \\
\hline No & $31(68.9)$ & \\
\hline
\end{tabular}

${ }^{a}$ Median (25-75th percentile). ALL, acute lymphoblastic leukemia; CNS, central nervous system.

cytogenetic abnormalities, such as translocations, and invasion of the CNS by leukemic cells.

Univariate and multivariate logistic regression analyses were performed to determine which of the parameters, such as age, sex, presence of translocations, initial leukocyte count and CNS invasion, in addition to YKL-40 plasma levels, were associated with the survival of children with ALL (Table II). Univariate and multivariate regression analyses in this study revealed that sex and the presence of translocations were not associated with survival in children with ALL. By contrast, age, initial leukocyte count, CNS invasion and YKL-40 plasma levels were found to be associated with survival in children with ALL. High-risk children with ALL were 8.53 times more likely to succumb to the disease compared with their low-risk counterparts [95\% confidence interval (CI): 1.2-58.2; $\mathrm{P}=0.03$ ]. Children with ALL with CNS invasion had a 6.45-fold higher risk of death compared with those without CNS invasion $(95 \% \mathrm{CI}$ : 1.01-41.2; $\mathrm{P}=0.04)$. Children with ALL who had high levels of YKL-40 ( $\geq 36.34 \mathrm{ng} / \mathrm{ml})$ had a 6.06-fold higher risk of death compared with those with low levels $(<36.34 \mathrm{ng} / \mathrm{ml}$; $95 \% \mathrm{CI}$ : 1.1-31.6; $\mathrm{P}=0.03$ ). Low-risk children with ALL with high plasma levels of YKL-40 (>36.34 ng/ml) may develop an infection with associated inflammation, which is a characteristic sign of ALL, leading to an increase in the plasma levels of YKL-40 (Table II).

Association of YKL-40 plasma levels with survival in children with ALL. Measurement of YKL-40 plasma levels revealed that the median YKL-40 level was significantly higher in children who had succumbed to the disease during the study $(55.1 \mathrm{ng} / \mathrm{ml})$ compared with that in children who remained alive $(31.53 \mathrm{ng} / \mathrm{ml} ; \mathrm{P}<0.05)$. YKL-40 is a protein the levels of which increase in the presence of inflammation, and it is considered as an independent marker of inflammation $(8,18)$. Patients who remained alive and exhibited high levels of YKL-40 likely had a prominent inflammatory response, which led to the increase of the YKL-40 levels(Fig. 1B).

Children with ALL were followed up for 36 months; during this period, $16(35.5 \%)$ succumbed to the disease and $29(64.5 \%)$ remained alive. The follow-up was complete for all the patients. Kaplan-Meier analysis revealed a positive association between overall survival and the plasma levels of YKL-40. As shown in Fig. 2A, children with ALL who 

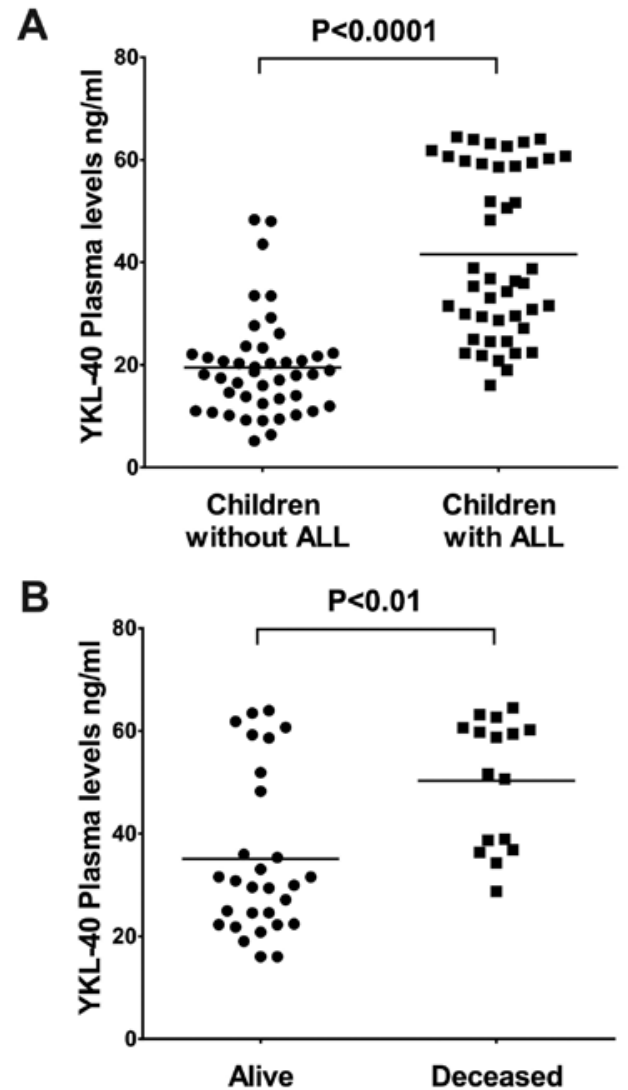

Figure 1. YKL-40 plasma levels in the study population. (A) YKL-40 plasma levels in children with and those without ALL. Absolute value plot showing YKL-40 plasma levels $(\mathrm{ng} / \mathrm{ml})$ in children without ALL $(\mathrm{n}=45)$ and children with ALL $(n=45)$. The horizontal solid lines represent the median values. YKL-40 plasma levels in children with ALL were significantly higher (median, $59.7 \mathrm{ng} / \mathrm{ml}$ ) compared with those in children without ALL (median $22.5 \mathrm{ng} / \mathrm{ml}$ ); P<0.0001 (Mann-Whitney U test). (B) YKL-40 plasma levels in alive and deceased children with ALL. Absolute value plot showing plasma YKL-40 values $(\mathrm{ng} / \mathrm{ml})$ in children with ALL who remained alive $(n=29,64.4 \%)$ and those who succumbed to the disease $(n=16,35.6 \%)$. The horizontal solid lines represent the median values. YKL-40 plasma levels in deceased children with ALL (median, $55.1 \mathrm{ng} / \mathrm{ml}$ ) were significantly higher compared with those in surviving children with ALL (median, $31.53 \mathrm{ng} / \mathrm{ml}$ ); $\mathrm{P}<0.01$ (Mann-Whitney U test). ALL, acute lymphoblastic leukemia.

had high YKL-40 plasma levels ( $\geq 36.34 \mathrm{ng} / \mathrm{ml}$ ) had shorter survival times compared with those with low YKL-40 plasma levels $(<36.34 \mathrm{ng} / \mathrm{ml}$; log-rank $\mathrm{P}=0.008)$. The cut-off value of $36.34 \mathrm{ng} / \mathrm{ml}$ was based on the median value obtained from the YKL-40 plasma levels in children with ALL in the present study. Kaplan-Meier analysis was performed with variables of poor prognosis in ALL, such as age, sex, presence of translocations, initial leukocyte count and CNS invasion. Kaplan-Meier analysis revealed a positive association of overall survival with age and CNS invasion. As shown in Fig. 2C, Kaplan-Meier analysis was performed in children with ALL grouped by age (low-risk, children aged 1-10 years; and high-risk, children aged $<1$ and $>10$ years), and it was observed that children with ALL aged $<1$ and $>10$ years exhibited a shorter survival compared with those aged 1-10 years (log-rank $\mathrm{P}=0.001)$. As shown in Fig. 2D, children with ALL with CNS invasion had a shorter survival compared with those without CNS invasion (log-rank $\mathrm{P}=0.032$ ). Sex, presence or absence of translocations and initial leukocyte count were not associated with the overall survival of children with ALL in the present study (Fig. 2B, E and F).

\section{Discussion}

Ongoing research is aimed at identifying novel biomarkers that may help determine the prognosis of patients with ALL. Several studies to date have demonstrated that YKL-40 may serve as a prognostic biomarker in patients with different types of malignancies, including lung cancer, breast cancer, cholangiosarcoma and glioma (23-27). YKL-40 levels were previously evaluated in tissue samples from healthy individuals using immunohistochemistry, where the YKL-40 staining intensity was higher in tissues that exhibited high metabolic activity compared with those with low activity (28).

In the present study, the plasma levels of YKL-40 were analyzed in 45 children with ALL who were aged 1-18 years. The pathological parameters associated with survival in children with ALL are as follows: i) Age: Patients aged $<1$ and $>10$ years are considered as high-risk and may have an unfavorable prognosis; ii) sex: Female patients have a better prognosis compared with male patients, primarily due to the appearance of testicular infiltrates that lead to a higher risk of relapse $(4,5)$; iii) initial leukocyte count: An initial leukocyte count of $50,000 / \mathrm{mm}^{3}$ is the cut-off value that determines favorable or dismal prognosis; patients with a count greater than this cut-off value are considered as high-risk (4); iv) cytogenetic abnormalities, such as translocations: The presence of $t(12 ; 21)$ is associated with a good prognosis, while $t(9 ; 22)$ and $t(1 ; 19)$ are considered to be associated with poor prognosis, since patients who harbor these cytogenic abnormalities have a lower rate of resolution of the disease (4,29); and v) invasion of the CNS by leukemic cells, which is also considered as a poor prognostic factor (30).

The statistical analyses suggested that high plasma levels of YKL-40 are associated with shorter survival, as well as with poor prognostic factors, such as age, leukocyte count at the time of diagnosis and CNS invasion, whereas they were not associated with other prognostic factors, such as the presence of translocations and sex. Our statistical analysis also suggested that, in addition to the association of high plasma YKL-40 levels with survival, other variables, such as age and CNS invasion, were also associated with the survival of children with ALL in this study.

The present study demonstrated that YKL-40 plasma levels were elevated in children with ALL, which was also consistent with other studies that found high serum or plasma levels of YKL-40 in different types of solid cancers, and were associated with shorter survival durations in patients with cholangiosarcoma, breast, lung, bladder and endometrial cancer (23-27). It has also been reported that high levels of YKL-40 may be associated with poor prognostic factors; for example, high levels of YKL-40 in patients with breast cancer were associated with higher tumor-node-metastasis stage (23). High serum levels of YKL-40 were associated with more advanced disease stage in small cell lung cancer (25) and International Federation of Gynecology and Obstetrics stage of endometrial cancer (26).

YKL-40 has been shown to increase tumor growth, metastatic potential and angiogenesis $(31,32)$. At the cellular level, YKL-40 protein expression is high in fetal and embryonic tissues, which are characterized by morphogenetic changes and marked cell proliferation and differentiation (6). No specific cell surface or soluble receptor for this protein has been identified 


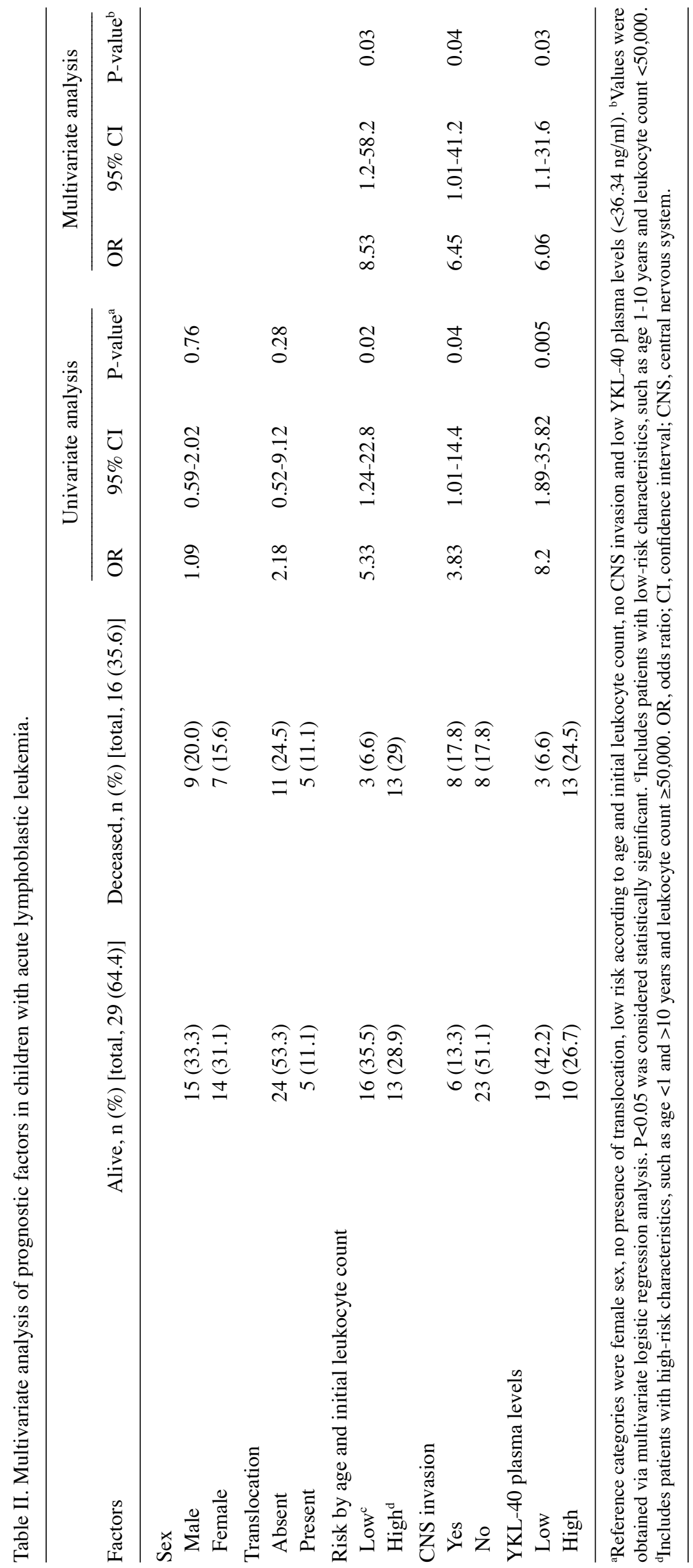


A

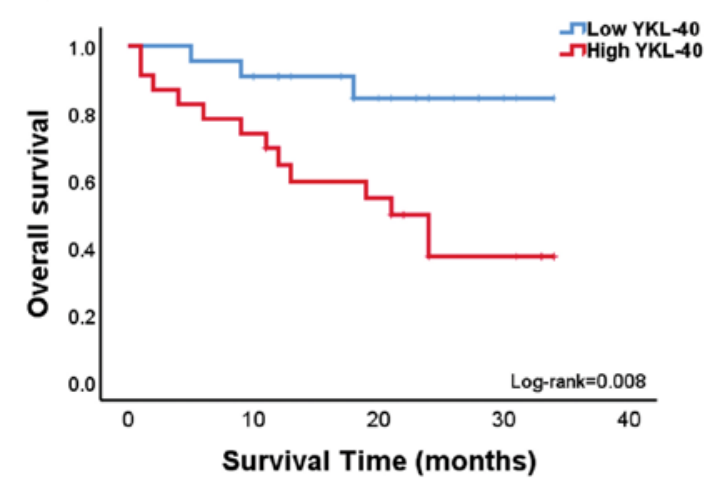

C

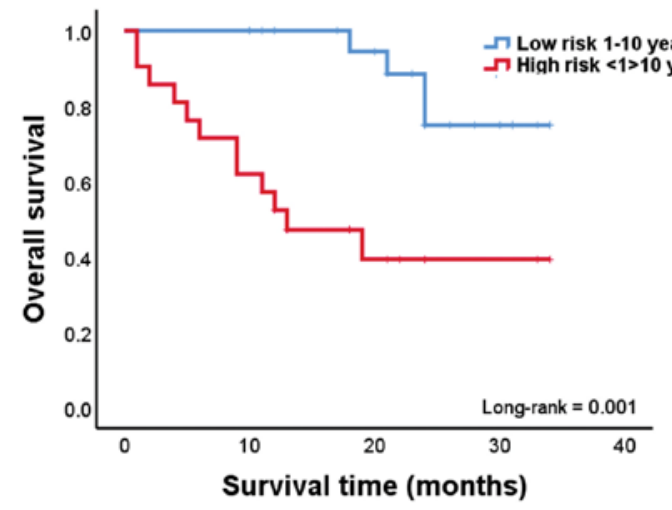

$\mathbf{E}$

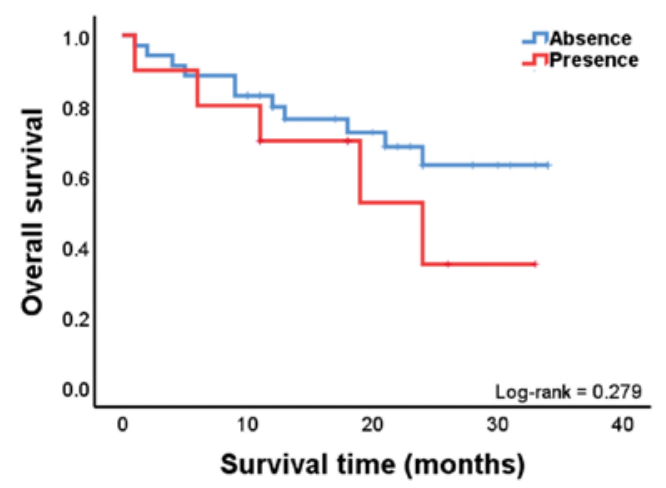

B

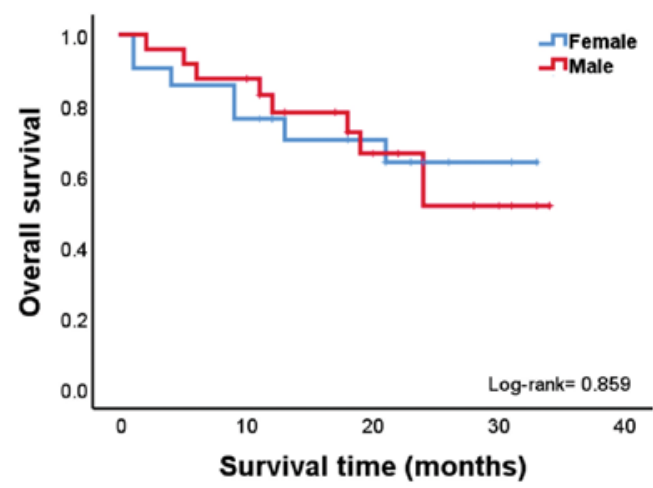

D

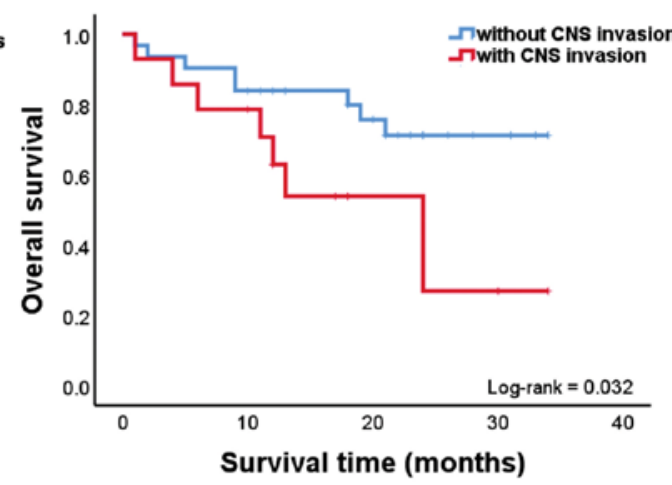

$\mathbf{F}$

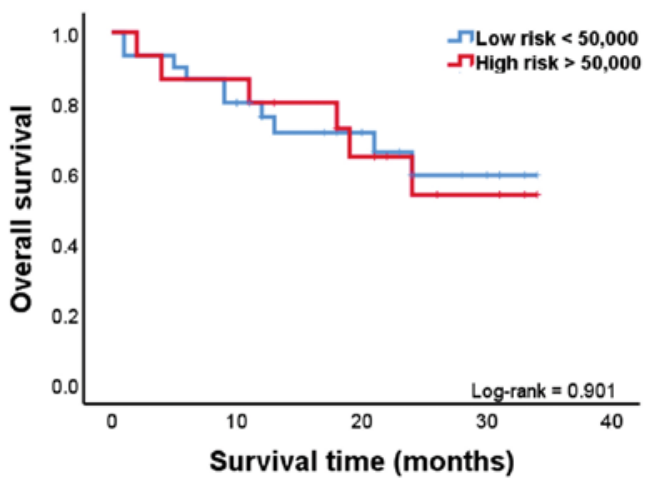

Figure 2. Kaplan-Meier curves for the effect of YKL-40 plasma levels and prognostic factors on overall survival time. (A) Kaplan-Meier curve for the effect of YKL-40 plasma levels on overall survival. Overall survival was significantly shorter for children with high YKL-40 plasma levels ( $\geq 36.34 \mathrm{ng} / \mathrm{ml}) \mathrm{compared}$ with that for children with low YKL-40 plasma levels ( $<36.34 \mathrm{ng} / \mathrm{ml}$; P=0.008). (B) Kaplan-Meier curve for the effect of sex on overall survival of children with ALL. The variable of sex was not associated with overall survival in children with ALL ( $\mathrm{P}=0.859)$. (C) Kaplan-Meier curve for the effect of age on overall survival in children with ALL. Overall survival was significantly shorter for children with ALL aged $<1$ and $>10$ years (high-risk group) compared with that for children aged 1-10 years (low-risk group; $\mathrm{P}=0.001$ ). (D) Kaplan-Meier curve for the effect of CNS invasion on overall survival in children with ALL. Overall survival was significantly shorter for children with CNS invasion compared with that for children without CNS invasion ( $\mathrm{P}=0.032)$. (E) Kaplan-Meier curve for the effect of translocations on overall survival. The presence of translocations was not associated with overall survival in children with ALL (P=0.279). (F) Kaplan-Meier curve for the effect of initial leukocyte count on overall survival in children with ALL. Initial leukocyte count was not associated with overall survival time in children with ALL ( $\mathrm{P}=0.901)$. ALL, acute lymphoblastic leukemia; CNS, central nervous system.

to date. The growth of fibroblasts derived from osteoarthritic synovial fluid, fetal lungs and adult skin after stimulation with YKL-40 is similar to that when stimulated by insulin-like growth factor 1 (32). The expression of YKL-40 was found in a variety of tumors and cell lines derived from different types of tumors, such as those of the bone, brain, breast and lung (33). YKL-40 may play a role in the regulation of the Ras/mitogen-activated protein kinase (MAPK) pathway, which is one of the most extensively investigated signal transduction pathways related to mitogenesis and the conduction of anti-apoptotic and mitogenic signals. YKL-40 has also been linked to MAPK and phosphoinositide 3-kinase (PI-3K) signaling cascade in fibroblasts, which leads to the phosphorylation of extracellular signal-regulated kinase-1/2 and Akt-mediated signaling cascades that are associated with mitogenesis and cell survival. Dysregulated activation of these signaling pathways leads to proliferative and 
antiapoptotic responses that are implicated in the development of different types of cancer (34). YKL-40 can therefore play a direct or indirect role in the development of leukemia, as it has been reported that activation of the PI-3K/Akt pathway is associated with poor prognosis and drug resistance in pediatric patients with ALL. Inhibition of the PI-3K/Akt pathway leads to a decrease in cell proliferation in chronic lymphoblastic leukemia and AML $(35,36)$. High expression of YKL-40 in patients with leukemia may promote disease progression (20). It has been suggested that serum or plasma levels of YKL-40 may reflect certain aspects of tumor growth and cell proliferation and may be used as a biomarker for monitoring cancer patients during and after treatment (13).

The results of the present study are consistent with those published in 2013 by Hurmale et al (20), where they analyzed the plasma levels of YKL-40 in adult patients with leukemia, and observed that the plasma levels of YKL-40 were elevated in patients with leukemia compared with those in healthy individuals. However, in that study, the mean YKL-40 plasma levels in patients with leukemia was $168 \mathrm{ng} / \mathrm{ml}$, which was quite different from that obtained in the present study, which was $59.7 \mathrm{ng} / \mathrm{ml}$. This may be due to the age of the patients included in our study (mean age, $8.7 \pm 4.9$ years). YKL-40 levels increase with age and may be associated with lifestyle changes (37-39). YKL-40 plasma levels in both sexes are highly correlated with age, which is therefore an important factor to consider when conducting clinical studies on the role of YKL-40 in the prognosis of patients with cancer (40).

Several limitations are important to consider in the present study. This study had a small sample size, which was not sufficient for validation of the plasma levels of YKL-40 as a prognostic biomarker. It is necessary to increase the number of samples and investigate the specific role of YKL-40 in hematological malignancies. It was herein demonstrated that high plasma levels of YKL-40 are associated with poor prognosis in children with ALL. Therefore, YKL-40 may be a new useful biomarker for actual risk classification in the prognosis of patients with ALL, in Mexico as well as globally.

The findings of the present study provide evidence that high plasma YKL-40 levels, age and CNS invasion are associated with shortened survival in children with ALL. High plasma YKL-40 levels were also found to be correlated with poor prognostic factors, such as age, CNS invasion and high initial leukocyte count. To the best of our knowledge, this is the first study to elucidate the role of YKL-40 plasma levels in the prognosis of children with ALL; however, additional studies with larger cohorts are required to verify the role of YKL-40 in this type of cancer. Elevated YKL-40 protein levels may serve as a marker of poor prognosis and shorter survival in children with this hematological malignancy. However, our data may generate novel hypotheses regarding the effect of YKL-40 levels on the survival of patients with ALL, which will have to be confirmed in independent studies. In addition, in vitro studies are necessary to further elucidate the role of YKL-40 in ALL.

\section{Acknowledgements}

AARA was the recipient of a PhD scholarship from CONACYT (CVU/Becario: 2366757/211722). This manuscript is part of the doctoral dissertation project of AARA a student of the
Programa de Doctorado en Ciencias Biomédicas, Facultad de Ciencia Químico Bilógicas, Universidad Autónoma de Guerrero (UAGro), Chilpancingo, Guerrero, México. The authors wish to thank the State Cancer Institute 'Dr. Arturo Beltran Ortega' for the support provided.

\section{Funding}

The present study was supported by a grant from CONACYT, México (Fondo Sectorial de Investigación en Salud y Seguridad Social, FSSS01-C-2018-1; grant no. A3-S-47392). This study was also supported by Universidad Autónoma de Guerrero.

\section{Availability of data and materials}

The datasets used and/or analyzed during the current study are available from the corresponding author on reasonable request.

\section{Authors' contributions}

AARA conducted the experiments, analyzed the data and wrote the paper. YGG, JON and MALV analyzed the data and wrote the paper. MALV and BIA contributed the reagents and materials. EIS, MVSH, MAJL and ABRR provided the biological samples and clinical data of the patients. AARA, MALV, YGG and JON are responsible for and can confirm the authenticity of the raw data. All the authors have read and approved the final manuscript.

\section{Ethics approval and consent to participate}

This study was performed with the approval of the Ethics Committee of the State Cancer Institute of the State of Guerrero. The parents or guardians of all the subjects signed informed consent forms. All procedures followed were in accordance with the ethical standards of the responsible committees on human experimentation (institutional and national) and with the principles outlined in the Helsinki Declaration.

\section{Patient consent for publication}

Not applicable.

\section{Competing interests}

The authors declare that they have no competing interests.

\section{References}

1. Centro Nacional para la Salud de la Infancia y la Adolescencia. (CENSIA): Comportamiento epidemiológico del cáncer en menores de 18 años. México 2008-2014. Secretaria de Salud, 2014. http://censia.salud.gob.mx/contenidos/descargas/cancer/20160601_ Boletin2014_SEDP12sep16_4.pdf

2. Smith MA, Seibel NL, Altekruse SF, Ries LA, Melbert DL, O'Leary M, Smith FO and Reamen GH: Outcomes for children and adolescents with cancer: Challenges for the twenty-first century. Int J Clin Oncol 28: 2625-2634, 2010.

3. Rendón-Macías ME, Reyes-Zepeda NC, Villasís-Keever MÁ, Meneses-SJ and Núñez AE: Tendencia mundial de la supervivencia en pacientes pediátricos con leucemia linfoblástica aguda. Revisión de las últimas cuatro décadas. Bol Med Hosp Infant Mex 69: 153-163, 2012. 
4. Layton-Tovar C: Factores de pronóstico en leucemia linfoblástica aguda pediátrica: Posibles marcadores moleculares. Rev Med Investig 3: 85-91, 2015.

5. Terwilliger T and Abdul-Hay M: Acute lymphoblastic leukemia: A comprehensive review and update. Blood Cancer J 7: e577, 2017.

6. Johansen JS, Hoyer PE, Larsen LA, Price PA and Møllgård K: YKL-40 protein expression in the early developing human musculoskeletal system. J Histochem Cytochem 55: 1213-1228, 2007.

7. Johansen JS, Jensen BV, Roslind A, Nielsen D and Price P: Serum YKL-40, a new prognostic biomarker in cancer patients? Cancer Epidemiol Biomarkers Prev 15: 194-202, 2006.

8. Prakash M, Bodas M, Prakash D, Nawani N, Khetmalas M, Mandal A and Eriksson C: Diverse pathological implications of YKL-40: Answers may lie in 'outside-in' signaling. Cell Signal 25: 1567-1573, 2013.

9. Chen HT, Zheng JM, Zhang YZ, Yang M, Wang YL, Man XH, Chen Y, Cai QC and Li ZS: Overexpression of YKL-40 predicts poor prognosis in patients undergoing curative resection of pancreatic cancer. J Pancreas 46: 323-334, 2017.

10. Kang EJ, Jung H, Woo OH, Park KH, Woo SU, Yang DS, Kim AR, Lee JB, Kim YH, Kim JS and Seo JH: YKL-40 expression could be a poor prognostic marker in the breast cancer tissue. Tumor Biol 35: 277-286, 2014.

11. Steponaitis G, Skiriutè D, Kazlauskas A, Golubickaitè I, Stakaitis R, Tamašauskas A and Vaitkienè P: High CHI3L1 expression is associated with glioma patient survival. Diagn Pathol 11: 42, 2016.

12. Erturk K, Tas F, Serilmez M, Bilgin E and Yasasever V: Clinical significance of serum Ykl-40 (chitinase-3-like-1 protein) as a biomarker in melanoma: An analysis of 112 Turkish patients. Asian Pac J Cancer Prev 18: 1383-1387, 2017.

13. Schultz NA and Johansen JS: YKL-40-A protein in the field of translational medicine: A role as a biomarker in cancer patients? Cancers (Basel) 2: 1453-1491, 2010.

14. Volck B, Johansen JS, Stoltenberg M, Garbarsch C, Price PA, Ostergaard M, Ostergaard K, Løvgreen-Nielsen P, Sonne-Holm S and Lorenzen I: Studies on YKL-40 in knee joints of patients with rheumatoid arthritis and osteoarthritis. Involvement of YKL-40 in the joint pathology. Osteoarthritis Cartilage 9: 203-214, 2001.

15. Chupp GL, Lee CG, Jarjour N, Shim YM, Holm CT, He S, Dziura JD, Reed J, Coyle AJ, Kiener P, et al: A chitinase-like protein in the lung and circulation of patients with severe asthma. N Engl J Med 357: 2016-2027, 2007.

16. Letuve S, Kozhich A, Arouche N, Grandsaigne M, Reed J, Dombret MC, Kiener PA, Aubier M, Coyle AJ and Pretolani M: YKL-40 is elevated in patients with chronic obstructive pulmonary disease and activates alveolar macrophages. J Immunol 181: 5167-5173, 2008.

17. Boot RG, Van Achterberg TA, Van Aken BE, Renkema GH, Jacobs MJ, Aerts JM and de Vries CJ: Strong induction of members of the chitinase family of proteins in atherosclerosis. Chitotriosidase and human cartilage gp-39 expressed in lesion macrophages. Arterioscler Thromb Vasc Biol 19: 687-694, 1999.

18. Rathcke CN, Johansen JS and Vestergaard H: YKL-40, a biomarker of inflammation, is elevated in patients with type 2 diabetes and is related to insulin resistance. Inflamm Re 55: 53-59, 2006.

19. Bergmann OJ, Johansen JS, Klausen TW, Mylin AK, Kristensen JS, Kjeldsen E and Johnsen HE: High serum concentration of YKL-40 is associated with short survival in patients with acute myeloid leukemia. Clin Can Res 11: 8644-8652, 2005

20. Hurmale AK, Choudhary SK, Bhaskar SK, Jatawa SK, Yadav M and Tiwari A: Overexpression of chitinase like protein YKL-40 in leukemia patients. J BioSci Biotech 2: 215-220, 2013

21. Organista-Nava J, Gómez-Gómez Y, Illades-Aguiar B Del Carmen Alarcón-Romero L, Saavedra-Herrera MV, Rivera-Ramírez AB, Garzón-Barrientos VH and Leyva-Vázquez MA: High miR-24 expression is associated with risk of relapse and poor survival in acute leukemia. Oncol Rep 33: 1639-1649, 2015.

22. US Food and Drug Administration: Clinical trial endpoints for the approval of cancer drugs and biologics: Guidance for industry. https://www.fda. gov/media/71195/download. Published December 2018. Accessed August 14, 2019.

23. Wang D, Zhai B, Hu F, Liu C, Zhao J and Xu J: High YKL-40 serum concentration is correlated with prognosis of Chinese patients with breast cancer. PLoS One 7: e51127, 2012.
24. Thongsom S, Chaocharoen W,Silsirivanit A,WongkhamS,SripaB, Choe H, Suginta W and Talabnin C: YKL-40/chitinase-3-like protein 1 is associated with poor prognosis and promotes cell growth and migration of cholangiocarcinoma. Tumor Biol 37: 9451-9463, 2016

25. $\mathrm{Xu} \mathrm{CH}, \mathrm{Yu} \mathrm{LK}$ and Hao KK: Serum YKL-40 level is associated with the chemotherapy response and prognosis of patients with small cell lung cancer. PLoS One 9: e96384, 2014

26. Kotowicz B, Fuksiewicz M, Jonska-Gmyrek J, Wagrodzki M and Kowalska M: Preoperative serum levels of YKL 40 and CA125 as a prognostic indicators in patients with endometrial cancer. Eur J Obstet Gynecol Reprod Biol 215: 141-147, 2017.

27. Zhang JP, Yuan HX, Kong WT, Liu Y, Lin ZM, Wangs WP and Guo JM: Increased expression of Chitinase 3-like 1 and microvessel density predicts metastasis and poor prognosis in clear cell renal cell carcinoma. Tumour Biol 35: 12131-12137, 2014

28. Ringsholt M,HogdallEV,Johansen JS, Price PA and Christensen LH: YKL-40 protein expression in normal adult human tissues-an immunohistochemical study. J Mol Histol 38: 33-43, 2007.

29. Borowitz MJ, Devidas M, Hunger SP, Bowman WP, Carroll AJ, Carroll WL, Linda S, Martin PL, Pullen DJ, Viswanatha D, et al: Clinical significance of minimal residual disease in childhood acute lymphoblastic leukemia and its relationship to other prognostic factors: A children's oncology groups study. Blood 111: 5477-5485, 2008.

30. Lenk L, Alsadeq A and Schewe DM: Involvement of the central nervous system in acute lymphoblastic leukemia: Opinions on molecular mechanisms and clinical implications based on recent data. Cancer Metastasis Rev 39: 173-187, 2020.

31. Shao R, Hamel K, Petersen L, Cao QJ, Arenas RB, Bigelow C, Bentley B and Yan W: YKL-40, a secreted glycoprotein, promotes tumor angiogenesis. Oncogene 28: 4456-4468, 2009.

32. Recklies AD, White $\mathrm{C}$ and Ling $\mathrm{H}$ : The chitinase 3-like protein human cartilage glycoprotein 39 (HC-gp39) stimulates proliferation of human connective-tissue cells and activates both extracellular signal regulated kinase- and protein kinase B-mediated signalling pathways. Biochem J 365: 119-126, 2002.

33. Johansen JS, Drivsholm L, Price PA and Christensen IJ: High serum YKL-40 level in patients with small cell lung cancer is related to early death. Lung Cancer 46: 333-340, 2004.

34. Sanchez VE, Nichols C, Kim HN, Gang EJ and Kim YM Targeting PI3K signaling in acute lymphoblastic leukemia. Int J Mol Sci 20: 412, 2019.

35. Hoellenriegel J,Meadows SA, SivinaM,WierdaWG,KantarjianH, Keating MJ, Giese N, O'Brien S, Yu A, Miller LL, et al: The phosphoinositide 3'-kinase delta inhibitor, CAL-101, inhibits B-cell receptor signaling and chemokine networks in chronic lymphocytic leukemia. Blood 118: 3603-3612, 2011.

36. Billottet C, Grandage VL, Gale RE, Quattropani A, Rommel C, Vanhaesebroeck B and Khwaja A: A selective inhibitor of the p110delta isoform of PI 3-kinase inhibits AML cell proliferation and survival and increases the cytotoxic effects of VP16. Oncogene 25: 6648-6659, 2006.

37. Bojesen SE, Johansen JS and Nordestgaard BG: Plasma YKL-40 levels in healthy subjects from the general population. Clin Chim Acta 412: 709-712,2011.

38. Johansen JS: Studies on serum YKL-40 as a biomarker in diseases with inflammation, tissue remodelling, fibroses and cancer. Dan Med Bull 53: 172-209, 2006.

39. Recklies AD, Ling $\mathrm{H}$, White $\mathrm{C}$ and Bernier SM: Inflammatory cytokines induce production of CHI3L1 by articular chondrocytes. J Biol Chem 280: 41213-41221, 2005.

40. Johansen JS, Lottenburger T, Nielsen HJ, Jensen JE, Svendsen MN, Kollerup G and Christensen IJ: Diurnal, weekly, and long-time variation in serum concentrations of YKL-40 in healthy subjects. Cancer Epidemiol Biomarkers Prev 17: 2603-2608, 2008.

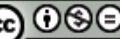

This work is licensed under a Creative Commons Attribution-NonCommercial-NoDerivatives 4.0 International (CC BY-NC-ND 4.0) License. 